\title{
Analysis of Kisan Mobile Advisory Text Message Sent to Farmers of Bagalkot District, India
}

\author{
G. Majeed*, Mouneshwari R. Kammar and Siddappa C. Angadi
}

ICAR-Krishi Vigyan Kendra, Bagalkot, University of Agricultural Sciences, Dharwad, India

*Corresponding author

A B S T R A C T

\section{Keywords \\ KVK, Mkisan portal, Text message}

Article Info

Accepted:

08 June 2018

Available Online:

10 July 2018
Information and communication technology (ICT) is developing very fast it has made its impact on lives of common man. The rapid development of communication technology has become a boon to farmers for getting timely and appropriate message as per the cropping season. In this regard Krishi Vigyan Kendra $(\mathrm{KVK})$ are acting as bridge between farmers and transfer of technology under the aegis of Indian Council of Agriculture Research in dissemination of these message to farmers'. The present study is aimed at to analysis of three year data of text messages sent by KVK Bagalkot to farming community.

\section{Introduction}

As per Telecom Regulatory Authority of India (TRAI) data of March, 2017, though there are about 40.56 crore mobile telephone connections in rural areas, internet penetration in the countryside is still abysmally low (in single digit percentage). With the advent of information technology the information flow has been fast now a day. To harness the advantage of this technology benefitting farmers in this context https://mkisan.gov.in website services are playing vital role This SMS Portal for farmers enables all Central and State government organizations in agriculture and allied sectors to give information/ services/advisories to farmers by SMS in their language, preference of agricultural practices and location.

SMS Portal was inaugurated by the Hon'ble President of India on July 16, 2013 and since its inception nearly 1671 crore messages have been sent to farmers throughout the length and breadth of the country. The number of Krishi Vigyan Kendra is increasing every year.

As part of agricultural extension (extending research from lab to the field), under the National e-Governance Plan - Agriculture (NeGP-A), various modes of delivery of services have been envisaged. These include internet, touch screen kiosks, agri-clinics, private kiosks, mass media, Common Service Centers, Kisan Call Centers, and integrated platforms in the departmental offices coupled 
with physical outreach of extension personnel equipped with pico-projectors and hand held devices. However, mobile telephony (with or without internet) is the most potent and omnipresent tool of agricultural extension. Krishi Vigyan Kendras funded by Indian Council of Agriculture Research by KVKs key link in transfer of Technology to farmers.

\section{Objectives of KMAS}

- To make SMS and other mobile based services as a tool of 2 way agricultural extension in which not only information/advisory services are provided to farmers as per his/her need in a broadcast mode (in keeping with selection of crop / agricultural practice, requirements and location) but they can also raise specific queries through Pull SMS or USSD.

- Making use of huge spread of mobile telephony in the rural areas to cover every farm household in the country to overcome the major impediment in bringing level playing field for small and marginal farmers. Presently, there are about 40 crore mobile telephones in rural areas

- A new objective of sending messages and acting as knowledge resource centre was added to mandate works of KVK in the last five years. Under this objective https:// mkisan.gov.in web based mobile advisory services are being provided to farmers with the financial support from ministry of agriculture and farmer welfare government of India.

- Centralized system wherein different modes of information flow are channelized and spread to the farmers in their own language.

- Integrated Portal to ensure proper storage in previous advisories/messages and also effective monitoring at various levels.

-. Integration of database of farmers from the
State Governments, Universities, KVKs web based registration, Kisan Call Centres etc.

- Since effective internet penetration in the rural areas is about $5 \%$ only, text messaging in the language of the farmer transcends the barriers of digital divide.

With these objective of https://mkisan.gov.in web based mobile advisory platform, KVK Bagalkot is disseminating various messages to farmers since 2013. However, the impact of this service was not quantified and there is felt need to study the impact of this message to improve upon the feedback from farmers hence the study.

\section{Materials and Methods}

The present study was carried out to assess the impact of https://mkisan.gov.in mobile advisory service sent through mobiles of registered farmers using https://mkisan.gov.in in regional language (Kannada) for the convenience of study.

The messages sent since last three years were considered. The total number of messages and total number of farmers to whom messages were sent in the district were considered, discipline wise classification of message was also computed. Farmers who visited KVK for various purposes were registered based on their willingness. Thus a total of 55000 farmers were registered under this service.

A subsample of 100 farmers was randomly selected for their feedback through telephone survey of registered farmers and also 50 who visited KVK receiving advisory sent by KVK Bagalkot were also assessed for their feedback on these services. Thus a total of 150 farmers were recruited for feedback study. Frequency and percentages were used to arrive at conclusion.

A subsample of 150 farmers was randomly 
selected and was assessed for the feedback. Feedback schedule prepared for this purpose was used. Feedback included 6 items pertaining to usefulness of the message. A constraint faced by the farmers in accessing this message was elicited. For measuring this variable the scoring procedures of constraints were measured on a given point scale ranging from very important (5), important(4), less important (3), least important and important (1). The possible highest score was 750 and the lowest score was 150 .

\section{Results and Discussion}

During 2015-16 a total of 33 different messages were sent and reached to 109515 farmers, during 2016-17 total 37 text messages were sent to 144098 and 31.57 percent increase in number of farmers registered compared to 2015-16.

During 2017-18 total 38 text message were sent to 467879 farmers and 224.695 percent increase in number of farmers registered as compared to 2016-17.

The number of messages sent and the number of farmers receiving message increased year by year. i.e. the number of messages from increased from 33 to 37 from 2005-16 to 2016-17, whereas number of message increased from 37 to 38 from 2016-17 to 2017-18.

On analysing of table 2 it is clear that, there were totally 108 messages sent to farmers since last three years. Major chunk of the message were pertaining to plant protection i.e. $37 \%$.

This indicates the fact that Bagalkot being agriculturally dominating district with 6.50 lakh cultivated area of which $30 \%$ is irrigated. Major crops being Sugarcane, Redgram, Summer groundnut, Chickpea, Pomegranate, Rabi sorghum. Hence, to address the problems pertaining to plant protection out of 108 message $37 \%$ messages were dedicated for plant protection.

To bring awareness about the scientific method of cultivation practices various training programme, Seminar, workshop and method demonstration programme implemented by KVK Bagalkot by sending text message about these events out 108 messages $23 \%$ of messages were pertaining for Awareness.

To educate the farmers about proper cultivation methods, weed management, irrigation timings text message sent were accounted $21 \%$ out of 108 messages and $\mathrm{s}$ $12 \%$ of message were pertaining to availability of quality seeds for both Kharif and Rabi season, planting material, bio control agents viz., Trichoderma, Metarihium and Pseduomonas and organic products like Vermicompost, Vermiwash and earthworms. This timely message was helpful farmers to get the information about the timely availability of agriculture products for the agriculture activities.

Only $7 \%$ of messages were pertaining to animal science. These messages about the animal vaccination timing, balanced diet of animals helped the registered farmers. There is a lot of scope for animal husbandry in Bagalkot district as there is $30 \%$ of the total area is under irrigation.

In the present study an analysis was made to analyse the kisan mobile advisories text messages sent to farmers of Bagalkot district. There were about 55,000 famers enrolled under this portal for KMAS, weekly message were sent to these farmers. A subsample of 150 farmers were randomly selected and were assessed for the feedback using schedule prepared for this purpose on important aspects (Fig. 1 and 2; Table 1-3). 
Table.1 Year wise number of text message sent to farmers

\begin{tabular}{|l|c|c|}
\hline Year & $\begin{array}{l}\text { No. of } \\
\text { messages }\end{array}$ & No. of. farmers \\
\hline $2015-16$ & 33 & 109515 \\
\hline $2016-17$ & 37 & 144098 \\
\hline $2017-18$ & 38 & 467879 \\
\hline
\end{tabular}

Table.2 Number of text message sent year wise and discipline wise

\begin{tabular}{|c|c|c|c|c|c|c|}
\hline Year & $\begin{array}{c}\text { Ag. } \\
\text { Entomology }\end{array}$ & Agronomy & $\begin{array}{c}\text { Animal } \\
\text { Science }\end{array}$ & Awareness & $\begin{array}{c}\text { Agri products of KVK } \\
\text { available for sale }\end{array}$ & Total \\
\hline $2015-16$ & 11 & 10 & 3 & 6 & 3 & 33 \\
\hline $2016-17$ & 17 & 4 & 2 & 9 & 5 & 37 \\
\hline $2017-18$ & 12 & 9 & 2 & 10 & 5 & 38 \\
\hline Total & 40 & 23 & 7 & 25 & 13 & \\
\hline
\end{tabular}

Table.3 Feedback of farmers through telephonic interview $(\mathrm{m}=150)$

\begin{tabular}{|l|l|c|c|c|}
\hline S1. No. & Parameters & Score & Mean & Rank \\
\hline $\mathbf{1}$ & Timely availability & 635 & 4.37 & I \\
\hline $\mathbf{2}$ & Accuracy & 425 & 2.83 & II \\
\hline $\mathbf{3}$ & Useful & 414 & 2.76 & III \\
\hline $\mathbf{4}$ & Readability & 280 & 1.87 & IV \\
\hline $\mathbf{5}$ & Poor Network & 132 & 0.88 & V \\
\hline $\mathbf{6}$ & Incompatibility of & 112 & 0.75 & VI \\
\hline
\end{tabular}

Brief overview of the mKisan Portal

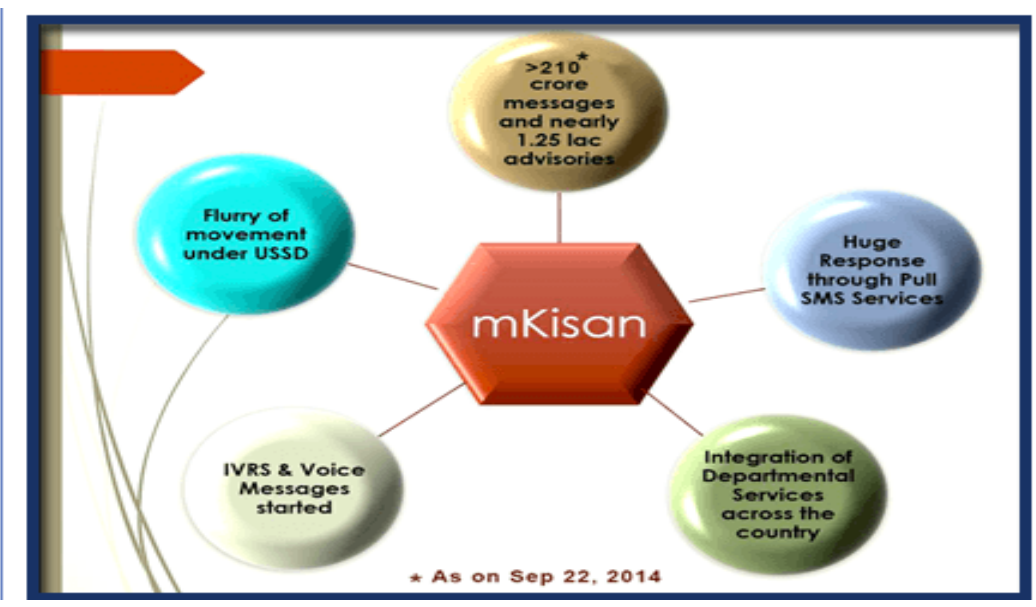

Fig.1 Number of text message sent year wise and discipline wise 


\section{No of messages sent since three years}

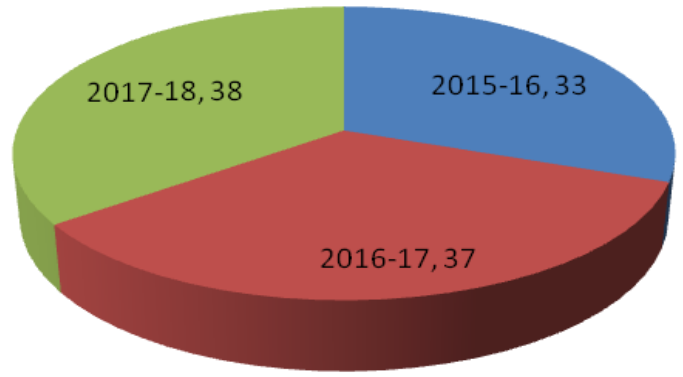

Fig.2 Feedback of farmers through telephonic interview $(m=150)$

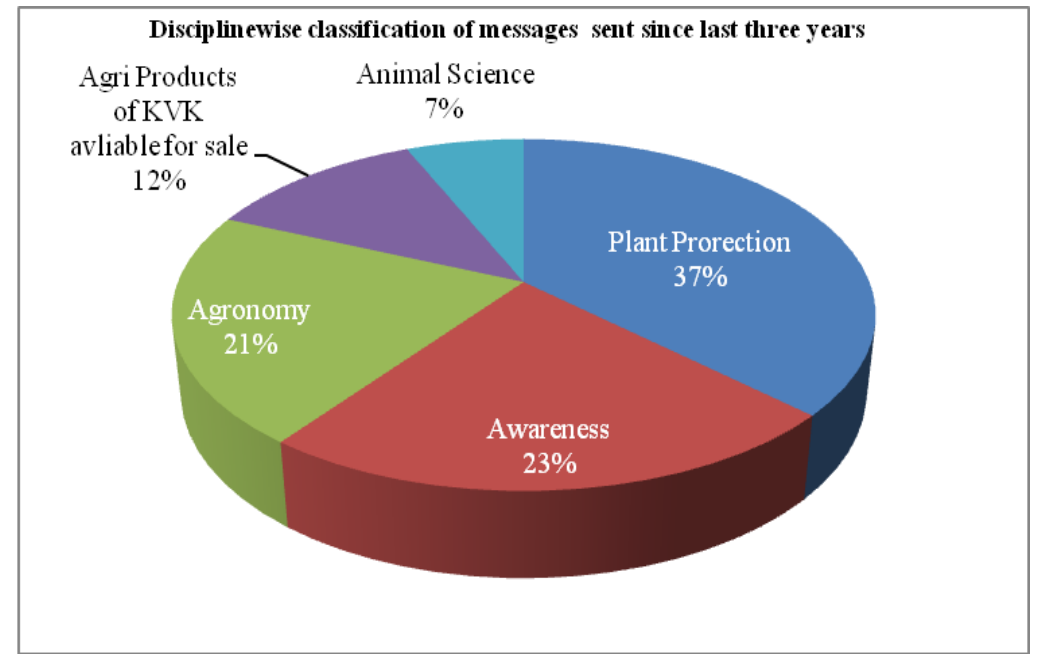

The results revealed that message related to plant protection were in larger number $(37 \%)$ followed by messages on awareness (23\%), agronomy (21\%), sale of quality seed and planting material $(12 \%)$ and animals science related messages $(7 \%)$. The feedback on these items were ranked and revealed that the messages were timely sent (Rank-I), accurate (Rank-II), useful (Rank-III), readable (Rank IV). The poor network in villages was also one of the constraints in accessing the messages, Poor Network (V) and incompatibility of handset (VI).
The conclusion from the results may inferred that, KMAS message were very helpful tips for farmers in need. There may be increased provision for frequency of messages per week i.e. least three message per week will cater to other disciplines which are less covered this issue needs to be addressed through policy intervention by the concerned authorities. Secondly the mobile handset may be designed so that it will be compatible with reading regional language facility. Another constraint during this study was mobile network which is a barrier for receiving message by farmers. 


\section{References}

1.Mobile Kisan website:https://mkisan.gov.in.

2.Telecom Regulatory and authority of India web portal www.trai.gov.in.

3. N. kusumkumari, Constraints Perceived by Agriculture Extension Personnel in Using M-tools Journal of Krishi Vigyan Year: 2018, Volume: 6, Issue: 2.
4.Ravikishore M (2014), Innovation in eAgricultural Extension Technologies(eAET): Diffusion and adoption of agriexpert systems among extension professionals in Kerala. M.Sc(Ag) thesis, Kerala Agricultural University Trivandrum, Kerala, 169P.

5.Bagalkot district website www.bagalkotkarnic.in

\section{How to cite this article:}

Majeed, G., Mouneshwari R. Kammar and Siddappa C. Angadi. 2018. Analysis of Kisan Mobile Advisory Text Message Sent to Farmers of Bagalkot District. Int.J.Curr.Microbiol.App.Sci. 7(07): 1241-1246. doi: https://doi.org/10.20546/ijcmas.2018.707.149 